\title{
Togitare
}

\section{ALEITAMENTO MATERNO DE CRIANÇAS COM MICROCEFALIA NO CONTEXTO DO ZIKA VÍRUS}

\author{
Floriacy Stabnow Santos ${ }^{1}$ (i) \\ Ada Oliveira Borges da Silva ${ }^{1}$ (i) \\ Antônia Sousa Lima ${ }^{1}$ (1) \\ Laise Sousa Siqueira ${ }^{1}$ (1) \\ Paula Gabrielle Gomes Candido ${ }^{1}$ (1) \\ Antônia Iracilda e Silva Viana ${ }^{1}$ (1) \\ Marcelino Santos Neto ${ }^{1}$ (D)
}

\section{RESUMO}

Objetivo: compreender a percepção de mães de crianças com microcefalia sobre o aleitamento materno.

Método: estudo descritivo, qualitativo, realizado no ambulatório de acompanhamento do Hospital Regional Materno Infantil de Imperatriz, Maranhão, Brasil, entre março e maio de 2019, com 12 mulheres. Incluíram-se mães que tiveram a síndrome do Zika no surto ocorrido entre 2015 e 2016 e conceberam crianças com microcefalia, e os depoimentos foram submetidos à análise de conteúdo. Resultados: com as falas, emergiram as categorias: sentimentos maternos diante da microcefalia; conhecimento das mães sobre microcefalia; microcefalia e amamentação; desafios no cuidado de um filho com microcefalia; perspectivas futuras de cuidados.

Considerações finais: amamentar no contexto do Zika contribui para a qualidade de vida das crianças com microcefalia. Este estudo contribui para a promoção do aleitamento materno às crianças com microcefalia visando à promoção e apoio dessa prática.

DESCRITORES: Percepção; Aleitamento Materno; Microcefalia; Zika Vírus; Enfermagem.

\section{LA LACTANCIA MATERNA DE NIÑOS CON MICROCEFALIA EN EL CONTEXTO DE VIRUS DE ZIKA}

\section{RESUMEN:}

Objetivo: comprender la percepción de madres de niños con microcefalia sobre la lactancia materna. Método: estudio descriptivo, cualitativo, realizado en un ambulatorio de seguimiento del Hospital Regional Materno Infantil de Imperatriz, Maranhão, Brasil, entre marzo y mayo de 2019, con 12 mujeres. Se incluyeron las madres que tuvieron el síndrome de Zika en el brote ocurrido entre 2015 y 2016 y concibieron niños con microcefalia, y los testimonios fueron sometidos a un análisis de contenido. Resultados: con los discursos, surgieron las categorías: sentimientos maternos frente a la microcefalia; conocimiento de la microcefalia por parte de las madres; microcefalia y la lactancia materna; desafíos en el cuidado de un hijo con microcefalia; perspectivas futuras de cuidados. Consideraciones finales: e lacto de amamantar en el contexto del virus de Zika contribuye a la calidad de vida de los niños con microcefalia. Este estudio contribuye a la promoción de la lactancia materna a los niños con microcefalia visando fomentar y apoyar esta práctica.

DESCRIPTORES: Percepción; Lactancia Materna; Microcefalia; Virus Zika; Enfermería. 
A microcefalia, segundo o Ministério da Saúde (MS)(1) é uma malformação congênita que acomete o desenvolvimento cerebral de um recém-nascido (RN) cujo perímetro cefálico (PC) apresenta medida menor que dois desvios-padrão abaixo da média específica para o sexo e idade gestacional(2).

Em abril de 2015, a população brasileira assistiu a um surto de casos envolvendo malformações congênitas, dentre as quais a microcefalia apresentava um número significativo em curto espaço de tempo. Além do retardo do desenvolvimento cerebral, os neonatos apresentavam alterações como artrogripose, malformação na coluna vertebral, microcalcificações no tecido neurológico, ventriculomegalia, malformações oculares e hipotrofia cortical ${ }^{(3)}$.

As aparições da microcefalia tiveram sua gênese em Pernambuco, e circundaram outros estados do nordeste. Desde então, a comunidade científica brasileira e internacional procurou respostas fidedignas diante das lacunas criadas relacionadas aos altos índices da microcefalia ${ }^{(3)}$, quando no decorrer dessas investigações foi encontrado material genético do Zika vírus (ZikaV) em amostras do líquido amniótico, corroborando para a sua correlação com a microcefalia ${ }^{(4)}$.

A Secretaria Estadual de Saúde de Pernambuco notificou a Secretaria de Vigilância em Saúde do Ministério da Saúde (MS) sobre o aumento do número de casos de microcefalia no estado e em novembro de 2015 foi declarada a Emergência em Saúde Pública de Importância Nacional (ESPIN) devido ao padrão atípico de ocorrência de microcefalia no Brasil(5). O ZikaV encontrou condições de sobrevivência entre 2013 e 2015 no Brasil, porque existia certa relação de causalidade: uma população exposta e um vetor em plena resistência através do ambiente e do clima ${ }^{(3)}$.

Entre janeiro de 2015 e setembro de 2017, 26 países das Américas notificaram 220.693 casos da síndrome de ZikaV e 579.700 casos suspeitos. No Brasil, notificaram-se 4.120 casos em 2015, 8.613 em 2016, 2.658 em 2017, 1.728 em 2018 e 1.163 em 2019. O número de casos confirmados por ano de notificação foi 954 em 2015, 1.927 em 2016, 369 em 2017 e 178 em 2018. Em 2019, houve 55 casos confirmados ${ }^{(5)}$.

De 2000 a 2014, foram registrados 2.464 nascidos vivos com microcefalia no Brasil e só em 2015 foram registrados 1.608 casos. O coeficiente de prevalência de microcefalia ao nascer no Brasil foi 54,6 casos por 100 mil nascidos vivos ${ }^{(6)}$.

Segundo o Boletim Epidemiológico do MS, no Maranhão, os casos confirmados de alterações no crescimento e desenvolvimento relacionado à infecção do vírus ZikaV totalizaram 498 notificações, o que corresponde a 3,0\% da população. Desse número, obteve-se 186 casos confirmados, 43 casos prováveis, sete casos em investigação, 193 casos descartados, sete casos inconclusivos e 62 casos excluídos ${ }^{(7)}$.

Considerando as discussões geradas no contexto de surto do vírus no Brasil entre os anos 2015 e 2016, questionou-se acerca da possível transmissão do vírus às crianças pelo aleitamento materno. Apesar de o material genético do vírus ter sido detectado no leite materno de duas mães, a recomendação e incentivo à amamentação foram mantidos, já que não se identificou quaisquer replicações virais associadas à transmissão do ZikaV aos neonatos. Não há evidências científicas de transmissão da doença pelo leite materno ${ }^{(8)}$.

A maternidade carrega significados substanciais que levam as mães a gerarem expectativas sobre o filho. Sendo assim, outras questões podem influenciar a não adesão ao aleitamento, o que desencadeia o desmame precoce no contexto do ZikaV(9). No contexto da microcefalia, o aleitamento materno é benéfico, uma vez que favorece o desenvolvimento do Sistema Nervoso Central, e as mães devem ser aconselhadas a amamentar seus filhos ${ }^{(5)}$. 
Segundo o MS, há grande impacto emocional nas mulheres diante do contexto da síndrome do ZikaV. O momento de uma notícia diagnóstica de anomalia congênita desencadeia sentimentos contraproducentes que vão desde o choque e negação, até o despertamento da culpa, raiva, medo e insegurança ${ }^{(5)}$.

É necessário sustentar um diálogo aberto e respeitoso com as mães, proporcionando informações acerca de infecções, consequências e direitos e, principalmente, conservando um apoio psicossocial relevante ${ }^{(3)}$. Nesse contexto, este estudo objetiva compreender a percepção de mães de crianças com microcefalia sobre o aleitamento materno.

\section{MÉTODO}

Estudo qualitativo, descritivo, exploratório, desenvolvido no ambulatório do Hospital Regional Materno Infantil de Imperatriz (HRMI), maternidade pública de referência do sul maranhanse, nordeste brasileiro, que atende prematuros e crianças com risco aumentado de morbidades, contando com uma equipe multiprofissional responsável pela avaliação dessas crianças até cinco anos de vida.

No momento da pesquisa, eram acompanhadas 38 crianças no referido serviço. Os sujeitos foram mães cujos filhos apresentaram a microcefalia no contexto do ZikaV no surto que ocorreu entre 2015 e 2016, com idade mínima de 18 anos. Excluíram-se mães de filhos com microcefalia cuja causa não estivesse associada ao ZikaV, isto é, aquelas mães que não tivessem sido afetas pelo ZikaV durante a gestação.

Neste estudo, empregou-se a amostragem intencional e por saturação teórica ${ }^{(10)}$, obtida com a análise da $12^{\circ}$ entrevista. Ressalta-se que duas mães foram entrevistadas em seus domicílios visto que não compareciam mais no ambulatório para as consultas de seus filhos.

Os dados foram coletados em entrevista individual, que durou cerca de 20 minutos, em sala privativa no serviço ou nas residências, entre março e maio de 2019. Foi utilizado um formulário baseado em pesquisa realizada anteriormente ${ }^{(11)}$ no mesmo serviço contendo informações sobre os dados sociodemográficos das mães e clínicos das crianças, dividido em duas partes. A primeira com características maternas (idade, escolaridade, raça/cor, estado civil, ocupação, renda familiar, número de filhos, local do pré-natal) e do neonato (sexo, momento do diagnóstico da microcefalia, se apresentaram alterações congênitas além da microcefalia). A segunda, com perguntas abertas que exploraram o objeto de estudo que iniciou com a pergunta: o que você sabe sobre a microcefalia relacionada ao aleitamento materno?

A entrevista foi gravada e posteriormente transcrita na íntegra. Após as mães eram encaminhadas ao consultório de enfermagem para a consulta. As duas mães entrevistadas no domicílio foram orientadas a comparecer no HRMI para as consultas de acompanhamento.

A sistematização e análise dos dados foram realizadas por meio da análise de conteúdo temática ${ }^{(12)}$, emergindo cinco categorias temáticas: conhecimento das mães sobre microcefalia; sentimentos maternos diante da microcefalia; microcefalia e amamentação; desafios no cuidado de um filho com microcefalia; perspectivas futuras de cuidados.

Preservando a identidade das mães, utilizou-se pseudônimos relacionados a flores.

A presente pesquisa foi aprovada pelo Comitê de Ética em Pesquisa da Universidade Federal do Maranhão, sob o parecer n. 1.974.612 de 21/03/2017. 
Participaram da pesquisa 12 mulheres, entre 18 e 38 anos, concluíram o ensino médio sete (58\%), declararam-se pardas 10 (84\%) e casadas ou em união estável oito (67\%), eram donas de casa $11(92 \%)$, com renda família menor que um salário mínimo nove $(75 \%)$, tinham entre três e quatro filhos seis $(50 \%)$, fizeram o pré-natal na unidade básica de saúde 10 (83\%), com filhos do sexo masculino nove (75\%), tiveram o diagnóstico de microcefalia durante a gestação sete $(58 \%)$ e apresentaram microcefalia com outras alterações congênitas 10 (83\%).

\section{Conhecimento das mães sobre microcefalia}

Os relatos revelam o pouco conhecimento das mães sobre a microcefalia:

[...] Eu sei pouquinho, ainda não estou muito por dentro [...]. (Lírio)

[...] Ah assim eu não sei muito. Eu não sei muito em relação a ela, porque eu sou preguiçosa pra pesquisar, eu procuro mais sobre os outros [...]. (Orquídea)

[...] Não sei muito, mas sei o básico [...]. (Magnólia)

[...] No início foi bem difícil, bem difícil mesmo, muitas perguntas sem respostas[...]. (Violeta)

\section{Sentimentos maternos diante da microcefalia}

Analisando os relatos das mães ao serem questionadas sobre o momento da descoberta da malformação de seus filhos, perceberam-se diversos sentimentos:

[...] Você perde o chão, mas aí ao mesmo tempo você tem que achar de novo porque é tudo novo, aí vem o medo, vários sentimentos juntos[...]. (Tulipa)

[...] Eu fiquei muito triste porque eu imaginava que eu não sabia muito sobre a doença então eu fiquei super desesperada[...]. (Orquídea)

[...] Fiquei assim um pouco triste né em saber que ela tinha essa doença, eu tenho cinco filhos, ela é a quarta e eu nunca tive um filho assim, ela que nasceu assim, eu fiquei doidinha da minha cabeça[...]. (Girassol)

[...] Eu fiquei em choque, fiquei com ansiedade e início de depressão, mas eu já tô bem[...]. (Magnólia)

[...] Ah, foi muito difícil, não foi fácil não, em aceitar que ele tinha problema [...]. (Violeta)

[...] Foi um susto, ele foi um dos primeiros casos, eu saí de lá desesperada [...]. (Azaleia)

[...] Eu fiquei triste e com medo porque a gente não sabia o caso da microcefalia e a médica que me atendeu me explicou... Eu pensava e falava pro meu marido: passei seis anos para engravidar e dou pra ti um filho especial[...]. (Bromélia)

\section{Microcefalia e amamentação}

Diante das falas, observou-se que a maioria das mulheres conseguiu amamentar seus filhos, mesmo considerando as adversidades:

[...] Ela mamou por mais de um ano, um ano e três meses. Eu só tirei a amamentação porque ela tinha intolerância e eu fui orientada a tirar porque às vezes eu comia alguma 
coisa e fazia mal pra ela. [...]. (Orquídea)

[...] Ela mamou até os 10 meses porque nasceu os dentinhos e ela começou a morder o meu peito chegando a ferir mesmo[...]. (Camélia)

[...] O aleitamento materno é o principal alimento deles até os seis meses exclusivos, se a gente tiver condições de ofertar só o leite é muito bom pra eles. Graças a Deus eu pude amamentar meus dois filhos até seis meses exclusivamente[...]. (Rosa)

[...] Ele não sugava direito, ele tinha dificuldade pra sugar, meu peito doía um pouco, mas não chegou a ferir. Mas ele mamou até sete meses[...]. (Margarida).

[...] Ele não quis mamar, ele não mamou. Ele amamentou até três meses só que na sucção dele, ele mamava e soltava logo eu tinha que tá colocando na boca dele [...]. (Azaleia)

[...] Eu sei que é importante, mas ele não queria, eu ainda tentei[...]. (Rosa)

[...] Ele não quis mamar, ele não mamou. Meus dois últimos nenhum quis mamar e foi até bom porque ele é uma criança que não sabe diferenciar, se ele pegar o dedo ele morde daí eu fico pensando, se ele mamasse eu não teria nem peito. Mas foi porque ele não quis mesmo, porque eu insisti muito[...]. (Violeta)

\section{Desafios no cuidado de um filho com microcefalia}

Cuidar de um filho com microcefalia é um desafio a ser enfrentado diariamente, como se observou a seguir:

[...] Tudo é difícil porque ele é muito chorão, estressado, quando ele começa a chorar ele não para, só para por ele mesmo[...]. (Rosa)

[...] O que eu sinto mais dificuldade é por morar em cidade pequena. Como eu convivo com outras mães, eu vejo que a dificuldade é justamente essa, falta de acompanhamento do que eles precisam, a gente não tem e a gente tem que ficar correndo atrás de uma coisa que é direito deles mas que eles não tem [...]. (Tulipa)

[...] Alimentação porque tem dias que ele come tudo, mas tem outros que ele não quer comer nada. Eu queria que ele melhorasse na parte da alimentação porque ele não come bem, né[...]! (Bromélia)

[...] Não na verdade não acho muito difícil não! Ah, eu tenho muito apoio da minha família, nunca ouvi ninguém falando nada de preconceito não[...]. (Lírio)

[...] Hoje eu me considero uma pessoa mais tranquila, já sei lidar mais com ele com esse problema. Só em saber procurar ajuda e você ver que não tá sozinha já ajuda muito. [...]. (Violeta)

\section{Perspectivas futuras de cuidados}

Refletir sobre as perspectivas futuras parece um comportamento espontâneo a todo indivíduo. Elas expressaram seus sentimentos entre voz embargada e choro de emoção:

[...] [choro de emoção]. Você fez uma pergunta muito difícil pra mim. Porque os médicos dizem que ela é um anjinho, eles dizem que um dia ela vai partir, você tem que dar muito amor, ela pode a qualquer momento não estar comigo, nos grupos de apoio que eu participo com mães na mesma situação praticamente toda semana morre um. De pneumonia, engasgamento, febre, eu tenho pânico só em saber que ela está gripada, vou logo cuidando disso[...]. (Camélia)

[...] Ah!! É muito difícil, tem muita gente que chega, eu até respondo com grosseria, 
perguntam - Ah Ele vai andar? Ah... Ele vai falar? Eu não sei porque ninguém sabe das respostas né[...]. (Azaleia)

[...] Eu nem gosto muito de tá pensando no futuro, eu aprendi assim, com o tempo a não pensar. No começo, quando ele nasceu, eu ficava pensando como ia ser a gente faltava quase a enlouquecer. Então eu não gosto de pensar no futuro, eu gosto de agradecer a Deus pelas pequenas conquistas que ele vai tendo [...]. (Hortência)

[...] Eu imagino muita coisa do meu filho: estudar, crescer... imagino muitas coisas. Tenho orgulho muito grande de ser mãe de um filho especial. Não tenho preconceito[...]. (Lírio)

[...] Dela crescer, estudar e se desenvolver e ficar grande, ficar viva[...]! (Girassol)

[...] Que ele cresça saudável, estudar, crescer na vida, vencer na vida e andar [...]. (Magnólia)

\section{DISCUSSÃO}

A microcefalia é uma anomalia congênita rara de multicausalidade, caracterizada por alterações na função ou estrutura do sistema nervoso central (SNC). As causas estão relacionadas a fatores genéticos e exposição a fatores de risco como: desnutrição grave, exposição a substâncias nocivas (álcool, substâncias tóxicas e alguns medicamentos), infecções por sífilis, rubéola, toxoplasmose, citomegalovírus e herpes simples ${ }^{(2)}$. Em 2016, após estudos levantados em razão do surto de ZikaV, foi comprovada a associação desse vírus com a microcefalia(4).

A associação da microcefalia ao ZikaV levou um tempo significativo para sua confirmação, mulheres acometidas e a própria equipe de saúde se depararam com uma grande incógnita. O cenário era desconfortável para as famílias envolvidas e os cientistas não tinham respostas efetivas ${ }^{(3)}$. Percebeu-se que muitas mães desconheciam a complexidade da disfunção em seus filhos ou apresentavam conhecimento superficial.

A falta de conhecimento é preocupante, uma vez que dificulta um cuidado de qualidade, sendo importante compreender os mecanismos de transmissão do Zika. Nessa perspectiva, é essencial que as mães compreendam ainda todo o mecanismo de enfermidade que envolve seus filhos, para mensurar limites e necessidades que envolvem o processo do cuidado(13).

Quando a mãe está insegura para atender às necessidades de seu filho, ela pode ter sentimentos depressivos, ansiedade, negação, choque, culpa e frustração. A mulher afetada pelo Zika apresenta sinais de angústia durante a gravidez ou após o parto, demonstrados pela irritabilidade, raiva, culpa, vergonha, ou sintomas físicos como tremores, perda de apetite, choro, tristeza e ansiedade ${ }^{(14)}$.

As gestantes sentem emoções diversas, por isso, lidar com um diagnóstico difícil provoca sentimentos profundos e intensos, capazes de influenciar negativamente na saúde emocional das mulheres ${ }^{(15)}$. Algumas das mães entrevistadas relataram momentos de choque, sentimentos depressivos, negação e frustração.

Em estudo realizado em Fortaleza-CE, as mães relataram sentimentos semelhantes aos encontrados na presente casuística(16). Diante de uma epidemia como a ocasionada pelo ZikaV, as mães de crianças acometidas pela microcefalia apresentam um certo padrão do comportamento emocional com ansiedade, medo e incerteza, pois, vivenciar a experiência epidêmica pode configurar estresse psicossocial a longo prazo(17).

A maternidade traz para a mulher responsabilidades, momento em que há uma 
mudança no seu papel social, gerando conflitos internos ${ }^{(18)}$. Quando a gravidez apresenta mudança em seu curso natural, a carga emocional se potencializa, intensificando as preocupações ${ }^{(19)}$.

Ao longo do tempo, estratégias de apoio ao aleitamento materno lograram efeito, e houve uma maior adesão das mulheres ao amamentarem seus filhos exclusivamente até os seis meses de vida como preconiza o MS. A hipótese formada diante da associação do aleitamento materno e microcefalia questionava se seria possível manter uma amamentação progressiva nesse contexto. Embora existam dificuldades, as mudanças sociais, psicológicas e físicas ocorram, o instinto materno as motiva a cuidar dos seus filhos sem restrições ${ }^{(6)}$.

Para crianças com microcefalia, a oferta do leite materno é indispensável, pois proporciona, além do desenvolvimento da cavidade bucal e diminuição dos riscos de infecções respiratórias e alergias, estimula a musculatura orofacial, propiciando desenvolvimento no sistema motor oral(9). A OMS recomenda que as mulheres com suspeita ou confirmação de ZikaV amamentem seus filhos, visto que não há evidencias da transmissão do vírus através do leite materno ${ }^{(8)}$.

As principais dificuldades na amamentação relatadas entre crianças com malformações orofaciais são: sucção fraca, dificuldade de pega, refluxo de leite pelas narinas, engasgos, ganho de peso insuficiente, pouco leite, ingurgitamento mamário e trauma mamilar ${ }^{(9)}$. Tais dificuldades podem ser corrigidas com apoio multiprofissional, em especial pelo profissional enfermeiro, com orientações específicas como posição correta para amamentar e expressão manual do leite para amaciar o mamilo e aréola facilitando a saída do leite ${ }^{(11)}$.

No presente estudo, uma menor parcela das mulheres não obteve êxito na amamentação. Infere-se que as referidas mães, apesar de terem a ciência da necessidade de amamentar seus filhos, desistiram do processo. Estudo realizado em 2015 demonstrou resultados semelhantes, e algumas mães ofereceram leite artificial para seus filhos contribuindo para o desmame precoce ${ }^{(20)}$.

Amamentar no contexto do ZikaV é possível e contribui para a qualidade de vida das crianças com microcefalia. Barreiras poderão surgir, como a dificuldade da pega e sucção tardia(11), entretanto, é necessário que as nutrizes sejam incentivadas a não desistir. Por isso, os profissionais da saúde precisam estar atentos na atenção ao binômio mãe-filho, incentivando a amamentação.

Crianças diagnosticadas com microcefalia apresentam retardo no desenvolvimento motor e atraso mental(9). Encarar o cuidado diário do filho especial é desafiador, requer esforços redobrados para sanar suas necessidades básicas, e enfrentar estigmas sociais relacionados à imagem da criança. A doença pode resultar em sentimentos de culpa, vergonha e frustração, levando a incertezas quanto à capacidade de cuidado do filho(14).

Uma criança com síndrome congênita do ZikaV possui vulnerabilidades individuais e sociais, de saúde e econômicas. Para uma criança especial, surgem demandas econômicas no cotidiano familiar, devido aos altos custos de medicamentos, alimentação e transporte ${ }^{(21)}$, bem como de uma assistência especializada com o monitoramento do crescimento e desenvolvimento ${ }^{(22)}$.

Apesar da crise vivenciada por algumas mulheres ao longo do tempo de cuidado com seus filhos após a epidemia de 2015 e 2016, uma parcela das entrevistadas apresentou resposta adaptativa diante da situação, com o fortalecimento dos laços familiares ${ }^{(20)}$. A resiliência foi a resposta positiva demonstrada por algumas mães, pois apresentaram a possibilidade de cultivar perspectivas otimistas, ainda que persistissem obstáculos no processo de desenvolvimento dos infantes ${ }^{(23)}$.

Uma criança com microcefalia apresenta ora problema de saúde, ora risco de vida e necessidade de assistência médica constante, sendo necessários subsídios financeiros ${ }^{(23)}$. 
Apesar das dificuldades existentes no enfrentamento que envolve o adoecimento de um filho(24), algumas mulheres entrevistadas demonstraram expectativas positivas para suas crianças. O cuidado de um filho com diagnóstico da Síndrome Congênita do ZikaV envolve mudanças emocionais, espirituais, sociais e familiares, e há necessidade de uma rede de cuidados para a criança e a mãe ${ }^{(25)}$.

Como limitação, observou-se o não comparecimento de algumas mães às consultas de acompanhamento multiprofissional de seus filhos devido a dificuldades financeiras e outras que optaram por unidades mais especializadas no tratamento das crianças, localizadas na capital do Estado.

\section{CONSIDERAÇÕES FINAIS}

Os resultados apontaram que a maioria das mulheres conseguiu amamentar seus filhos, apesar dos fatores adversos que suas realidades apresentaram. A percepção das mães em relação ao aleitamento materno no contexto do ZikaV demonstrou que elas conhecem os benefícios da amamentação para o desenvolvimento motor-oral, neuropsicomotor e cognitivo, e a situação de padecimento das crianças tornou-se fundamental para a superação e a resiliência demonstrada por elas, ao persistir em alimentar seus filhos através do leite materno.

Percebeu-se dificuldade em relação à perspectiva de cuidado dos infantes e uma concepção incerta do futuro deles, sugerindo a estimulação da participação ativa da equipe de saúde para fortalecer, apoiar, incentivar e educar não só as mães, mas seus familiares.

Fica claro que a amamentação no contexto da microcefalia deve ser apoiada e priorizada como perspectiva de cuidado e saúde tanto para crianças, quanto para mulheres e sociedade, já que o aleitamento materno atribui benefícios ao indivíduo por toda a sua existência.

A contribuição desse estudo está em compreender os aspectos do aleitamento materno de crianças com microcefalia visando à promoção e apoio dessa prática.

\section{AGRADECIMENTOS}

A Pró-Reitoria de Extensão e Cultura da Universidade Federal do Maranhão. Este estudo foi financiado pela Coordenação de Aperfeiçoamento de Pessoal de Nível Superior Brasil (CAPES) - Código de Financiamento 001.

\section{REFERÊNCIAS}

1. Ministério da Saúde (BR). Secretaria de Vigilância em Saúde. Departamento de Vigilância das Doenças Transmissíveis. Protocolo de vigilância e resposta à ocorrência de microcefalia e/ou alterações do sistema nervoso central (SNC). [Internet] Brasília: Ministério da Saúde; 2015 [acesso em 27 jun 2019]. Disponível em: https://portalarquivos.saude.gov.br/images/pdf/2016/marco/24/Microcefalia-Protocolo-vigil--nciaresposta-versao2.1.pdf. 
2. Cabral CM, Nóbrega MEB da, Leite PL e, Souza MSF de, Teixeira DCP, Cavalcante TF, et al. Descrição clínico-epidemiológica dos nascidos vivos com microcefalia no estado de Sergipe, Brasil, 2015. Epidemiol. Serv. Saúde. [Internet]. 2017 [acesso em 27 jul 2019]; 26(2). Disponível em: https://doi.org/10.5123/s167949742017000200002.

3. Ministério da Saúde (BR). Secretaria de Vigilância em Saúde. Vírus Zika no Brasil: a resposta do SUS. [Internet]. Brasília: Ministério da Saúde; 2017. [acesso em 27 jun 2019]. Disponível em: http://bvsms. saude.gov.br/bvs/publicacoes/virus zika brasil resposta sus.pdf.

4. Rozetti IG, Pereira MG, Braga DC, Bonamigo EL, Bonatto K, Mozzer E. Infecção pelo Zika Vírus e seu nexo causal com casos de microcefalia no Brasil: uma revisão da literatura. APEjba. [Internet]. 2017 [acesso em 27 jul 2019]; 2(e:13456). Disponível em: https://portalperiodicos.unoesc.edu.br/apeuj/article/ view/13456.

5. Ministério da Saúde (BR). Secretaria de Vigilância em Saúde. Síndrome congênita associada à infecção pelo vírus Zika: situação epidemiológica, ações desenvolvidas e desafios, 2015 a 2019. Bol Epidemiol [Internet]. 2019 [acesso em 29 jul 2020]; 50(esp.). Disponível em: http://www.saude.gov.br/boletinsepidemiologicos.

6. Marinho F, Araújo VEM de, Porto DL, Ferreira HL, Coelho MRS, Lecca RCR, et al. Microcefalia no Brasil: prevalência e caracterização dos casos a partir do Sistema de Informações sobre Nascidos Vivos (Sinasc), 2000-2015. Epidemiol Serv Saude. [Internet]. 2016 [acesso em 27 jul 2019]; 25(4). Disponível em: https:// doi.org/10.5123/S1679-49742016000400004.

7. Ministério da Saúde (BR). Boletim Epidemiológico n. 39, vol.49. Secretaria de Vigilância em Saúde. [Internet]. Brasília: Ministério da Saúde; 2018 [acesso em 26 jun 2019]. Disponível em: https:// portalarquivos.saude.gov.br/images/pdf/2018/outubro/05/Vol.\%2049\%20N\%C2\%BA\%2039.pdf.

8. Sociedade Brasileira de Pediatria. Departamento científico de aleitamento materno. Guia Prático de Atualização. Doenças maternas infecciosas e amamentação. [Internet]. 2017 [acesso em 27 jul 2020]; 2. Disponível em: https://www.sbp.com.br/fileadmin/user upload/Aleitamento - DoencMat Infec e Amam. pdf.

9. Santos SFM dos, Soares FVM, Abranches AD de, Costa ACC da, Moreira MEL, Fonseca V de M. Infants with microcephaly due to ZIKA virus exposure: nutritional status and food practices. Nutrition Journal. [Internet]. 2019 [acesso em 26 jun 2019]; 18(4). Disponível em: http://dx.doi.org/10.1186/s12937-0190429-3.

10. Nascimento L de CN, Souza TV de, Oliveira IC dos S, Moraes JRMM de, Aguiar RCB de, Silva LF da. Theoretical saturation in qualitative research: an experience report in interview with schoolchildren. Rev. bras. enferm. [Internet]. 2018 [acesso em 26 jul 2020]; 71(1). Disponível em: http://dx.doi. org/10.1590/0034-7167-2016-0616.

11. Santos FS, Lima A de S, Viana Al e S, Santos LH dos, Santos Neto M, Costa ACP de J., Araújo MFM de. Aleitamento materno de crianças com microcefalia por zika vírus. Res Soc Dev [Internet]. 2020. [acesso em 28 jul 2020]; 9(6). Disponível em: http://dx.doi.org/10.33448/rsd-v9i6.3692.

12. Bardin L. Análise de conteúdo. São Paulo: Edições 70; 2011.

13. Nelson EJ, Luetke MC, Kianersi S, Willis E, Rosenberg M. Knowledge and perceptions of Zika virus transmission in the community of Puerto Plata, Dominican Republic. Bmc Infect Dis. [Internet]. 2019 [acesso em 26 jun 2019]; 19(339). Disponível em: http://dx.doi.org/10.1186/s12879-019-3952-0.

14. World Health Organization (WHO). Psychosocial support for pregnant women and for families with microcephaly and other neurological complications in the context of Zika vírus. Interim guidance for health-care providers [Internet]. 2016 [acesso em 26 jun 2019]. Disponível em: https://www.who.int/csr/ resources/publications/zika/psychosocial-support/en/.

15. Costa E dos S, Bonfim EG, Magalhães R de LB, Viana LMM. Mothers' experiences of children with microcephaly. Rev Rene. [Internet]. 2018 [acesso em 26 jun 2019]; 19(e:3453). Disponível em: http:// dx.doi.org/10.15253/2175-6783.2018193453. 
16. Campos MMMS, Sousa TC de, Teixeira GP, Chaves KY dos S, Araújo MVUM, Sousa MR. Challenges and perspectives of mothers of children with microcephaly due to Zika virus infection. Rev Rene.

[Internet]. 2018 [acesso em 26 jun 2019]; 19(e:32839). Disponível em: http://dx.doi.org/10.15253/21756783.20181932839.

17. Ebuenyl ID, Bhuyan SS, Bain LE. Zika Virus infection and microcephaly: anxiety burden for women. Pan African Medical Journal. [Internet]. 2018 [acesso em 26 jun 2019]; 30(2). Disponível em: http://dx.doi. org/10.11604/pamj.2018.30.2.11794.

18. Coelho DDR, Souza JLA de, Torres MM de SM, Drezett J. Gravidez e maternidade tardia: sentimentos e vivências de mulheres em uma unidade de pré-natal de alto risco em Barreiras, Bahia. Hígia. [Internet]. 2017 [acesso em 26 jun 2019]; 2(1). Disponível em: http://fasb.edu.br/revista/index.php/higia/article/ view/145/202.

19. Acheampong AK, Naab F, Kwashie A. Qualitative exploration of psychological reactions and coping strategies of breastfeeding mothers living with HIV in the Greater Accra Region of Ghana. Int Breastfeed J. [Internet]. 2017. [acesso em 26 jun 2019]; 12(28). Disponível em: http://dx.doi.org/10.1186/s13006-0170119-8.

20. Oliveira CS de, locca FA, Carrijo MLR, Garcia R de ATM. Breastfeeding and complications that contribute to early weaning. Rev. Gaúcha Enferm. [Internet]. 2015 [acesso em 26 jun 2019]; 36(spe). Disponível em: https://doi.org/10.1590/1983-1447.2015.esp.56766.

21. Ferreira HNC, Schiariti V, Regalado ICR, Sousa KG, Pereira SA, Fechine CPN dos S, Longo E. Functioning and Disability Profile of Children with Microcephaly Associated with Congenital Zika Virus Infection. Int. J. Environ. Res. Public Health. [Internet]. 2018 [acesso em 26 jun 2019]; 15(6). Disponível em: http://dx.doi.org/10.3390/ijerph15061107.

22. França TLB de, Medeiros WR, Souza NL de, Longo E, Pereira SA, França TB de O, Sousa KG. Growth and Development of Children with Microcephaly Associated with Congenital Zika Virus Syndrome in Brazil. Int. J. Environ. Res. Public Health. [Internet]. 2018 [acesso em 26 jun 2019]; 15(9). Disponível em: http://dx.doi.org/10.3390/ijerph15091990.

23. Giffoni Filho JAR. A resiliência e seus desdobramentos: a resiliência familiar. O Portal dos Psicólogos, Salvador (BA). [Internet]. 2019 [acesso em 25 jun 2019]; Disponível em: https://www.psicologia.pt/artigos/ ver artigo.php?codigo=A0806.

24. Barata ALSRB, Santos JS, Costa JM, Barbosa LNF, Santos EP. Impacto da microcefalia no subsistema fraterno por meio do teste da família: estudo de caso. Rev. SBPH [Internet]. 2019 [acesso em 26 jul 2019]; 22(1). Disponível em: http://pepsic.bvsalud.org/scielo.php?script=sci arttext\&pid=S151608582019000100009\&lng=pt.

25. Hamad GBNZ, Souza KV de. Filho especial, mãe especial: o sentido da força de mães de crianças com a síndrome congênita do zika vírus. Esc. Enf. Anna Nery. [Internet]. 2019 [acesso em 26 jul 2020]; 23(4). Disponível em: http://doi.org/10.1590/2177-9465-EAN-2019-0022. 


\section{COMO REFERENCIAR ESTE ARTIGO:}

Santos FS, Silva AOB da, Lima AS, Siqueira LS, Candido PGG, Viana Al e S, et al. Aleitamento materno de crianças com microcefalia no contexto do zika vírus. Cogitare enferm. [Internet]. 2021 [acesso em "colocar data de acesso, dia, mês abreviado e ano"]; 26. Disponível em: http://dx.doi.org/10.5380/ce.v26i0.72916.

Recebido em: 15/04/2020

Aprovado em: 03/08/2020

Editora associada: Tatiane Herreira Trigueiro

Autor Correspondente:

Floriacy Stabnow Santos

Universidade Federal do Maranhão - Imperatriz, MA, Brasil

E-mail: floriacys@gmail.com

Contribuição dos autores:

Contribuições substanciais para a concepção ou desenho do estudo; ou a aquisição, análise ou interpretação de dados do estudo - AOBS, ASL

Elaboração e revisão crítica do conteúdo intelectual do estudo - AOBS, LSS, PGGC, AISV, MSN

Aprovação da versão final do estudo a ser publicado - MSN

Responsável por todos os aspectos do estudo, assegurando as questões de precisão ou integridade de qualquer parte do estudo - FSS

Copyright $\odot 2021$ Este é um artigo em acesso aberto distribuído nos termos da Licença Creative Commons Atribuição, que permite o uso irrestrito, a distribuição e reprodução em qualquer meio desde que o artigo original seja devidamente citado. 